Revue des patrimoines

\title{
Au regard des métiers du patrimoine
} ÉDITORIAL

\section{Marie-Cécile Bouju et Christian Hottin}

\section{OpenEdition}

Journals

Édition électronique

URL : http://journals.openedition.org/insitu/13749

DOI : 10.4000/insitu. 13749

ISSN : 1630-7305

Éditeur

Ministère de la Culture

Référence électronique

Marie-Cécile Bouju et Christian Hottin, «Au regard des métiers du patrimoine », In Situ [En ligne], 30 |

2016, mis en ligne le 30 septembre 2016, consulté le 24 septembre 2020. URL : http://

journals.openedition.org/insitu/13749; DOI : https://doi.org/10.4000/insitu.13749

Ce document a été généré automatiquement le 24 septembre 2020.

\section{(c)}

In Situ Revues des patrimoines est mis à disposition selon les termes de la licence Creative Commons Attribution - Pas d'Utilisation Commerciale - Pas de Modification 4.0 International. 


\title{
Au regard des métiers du patrimoine
}

\author{
ÉDITORIAL
}

Marie-Cécile Bouju et Christian Hottin

1 Les 12, 13 et 14 mai 2014, les Archives nationales, la direction générale des Patrimoines, l'université Paris-8-Vincennes-Saint-Denis et Médiadix (université Paris-OuestNanterre-La Défense) ont organisé un colloque consacré aux « Métiers du patrimoine en France: identités, formations, interrelations professionnelles au service du patrimoine, $\mathrm{XIX}^{\mathrm{e}}-\mathrm{XXI}^{\mathrm{e}}$ siècles $»^{1}$ (fig. 1). Nous avons souhaité prolonger cette réflexion via la revue In Situ. 


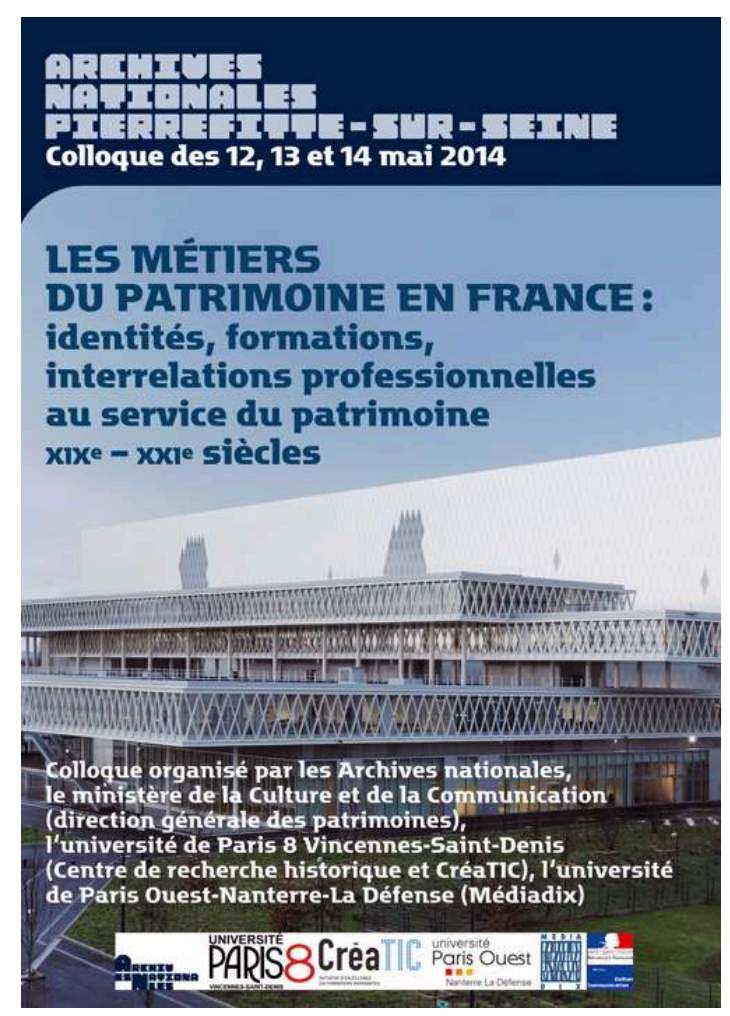

Affiche du colloque « Métiers du patrimoine en France : identités, formations, interrelations professionnelles au service du patrimoine, $\mathrm{XIX}$ - $\mathrm{XX|}$ siècles ».

(c) Archives nationales, Pôle Image, 2014.

2 Le numéro qui en résulte doit être replacé dans un contexte plus large de recherches sur le patrimoine. Il occupe du reste une place originale dans les tables - toutes virtuelles - de la revue In Situ, puisque c'est le premier opus exclusivement dédié non à un corpus patrimonial précis (le patrimoine rural, la villégiature, l'enseignement supérieur, etc.) mais à une réflexion sur les métiers du patrimoine (bien que cette perspective réflexive ait été présente en filigrane de certains des tout premiers dossiers - «Les horizons de l'Inventaire ", «Patrimoine en situation", "L'Inventaire entre histoire et prospective »). À ce titre, et sans en dévoiler ici les secrets de fabrication, le sommaire, le choix des articles, la problématique générale ont fait l'objet de discussions fournies au sein du comité de rédaction, discussions plus longues et plus incertaines parfois dans leurs développements que pour d'autres thèmes, pour lesquels un consensus s'établit rapidement autour d'une problématique. Grâce à ces débats, au cours desquels le comité de rédaction a pleinement joué son rôle d'intellectuel collectif, le périmètre initial d'étude, celui du colloque (archives, bibliothèques, musées) a été sensiblement élargi, et des contributions ont été envisagées pour mieux prendre en compte les métiers du patrimoine monumental et mobilier - objet premier et historique de la ligne éditoriale d'In Situ - et qui se trouvaient légèrement hors-champ par rapport au corpus d'études rassemblé à l'issue du colloque. Les contributions de Marie-Anne Sire (sur l'ensemble des métiers patrimoniaux), du collectif MoHiCan (emmené ici par Clémentine Albertoni, Sophie Loppinet et Enora Juhel, autour de l'histoire des recenseurs des Monuments historiques) ou encore de Christian Hottin (sur les ethnologues) prennent place dans cette extension du périmètre. 
3 En revanche, un critère de choix qui avait déjà été mis en œuvre lors du colloque se retrouve dans le présent dossier. L'ambition des coordinateurs a été et reste de proposer un ensemble d'études sur les métiers du patrimoine, fondées sur une démarche réflexive et scientifique, que ce soit en mobilisant des sources d'archives (comme pour Cécile Robin), en opérant des "pas de côté " géographiques (voir les exposés de Carol Couture ou Laurent Ferri), en instaurant un dialogue entre professionnel et chercheur en sciences sociales (avec la contribution de Léonie Hénaut et Anne-Elizabeth Rouault) ou encore en initiant une démarche prospective originale (à la manière d'Aurélien Joudrier dans son analyse des organigrammes de plusieurs grands musées français). De façon générale, nous avons souhaité éviter les «retours d'expérience » et les témoignages, tout autant que les descriptifs se rapprochant des éléments qui figurent dans les référentiels de métiers. Le dossier réalisé présente donc une originalité assez marquée: dans la grande majorité des cas en effet, il s'agit d'études conduites par des professionnels du patrimoine qui ont souhaité construire leur propre pratique professionnelle comme objet d'étude, usant pour cela de ressources méthodologiques variées.

4 Que sont donc les métiers du patrimoine ${ }^{2}$ ? D'après les dernières statistiques publiées par le Département des études, de la prospective et des statistiques (DEPS) du ministère de la Culture et de la Communication, 579000 personnes exercent en France une profession culturelle au titre de l'emploi principal ${ }^{3}$, dont plus de 56000 dans le domaine du patrimoine. Le DEPS regroupe dans ce dernier ensemble les bibliothécaires, les archivistes, les professionnels des musées et des monuments historiques, mais excluent les métiers d'art et les architectes. En faisant du patrimoine en France un champ d'intervention politique, la Révolution française fut aussi la matrice d'une nouvelle identité professionnelle. Le 25 nivôse an II (14 janvier 1794), la Commission temporaire des arts et la Commission d'instruction publique édictèrent des «Instructions sur la manière d'inventorier et de conserver, dans toute l'étendue de la République, tous les objets qui peuvent servir aux arts, aux sciences et à l'enseignement». Ce texte est considéré comme l'acte de naissance du professionnel du patrimoine, intermédiaire entre l'artiste et le gestionnaire, dont les compétences spécifiques sont mises au service du patrimoine. Pourtant, dès la Révolution française, ces compétences sont également revendiquées, ou même contestées, par d'autres acteurs (politiques, artistes, érudits...) ${ }^{4}$. Faut-il y voir une concurrence entre groupes professionnels en quête de légitimité et de supériorité sociale, économique, voire politique?

5 En France, cette question est complexe à traiter du fait du vocabulaire utilisé. Parlonsnous de métier, profession, corps, statut, groupe ? L'histoire du patrimoine en France, et la place de la fonction publique dans sa construction, ont souvent conduit à la confusion, pour le grand public comme pour les "professionnels», entre ces mots et leur représentation sociale, comme par exemple la qualification de "chartiste », qui est un titre (archiviste paléographe) et non un métier, ou celle de "conservateur de musée » qui est un statut - même si le corps précis est celui de "conservateur du patrimoine ». La profession est le métier qu'un individu déclare exercer, le métier est l'activité qu'il exerce effectivement et qui lui procure un revenu. Nous avons choisi ici, par commodité, de traiter du métier.

6 Ce nouveau numéro d'In Situ peut être appréhendé selon deux perspectives complémentaires. En suivant la première, historique, il apparait comme un jalon supplémentaire dans une tradition déjà fort ancienne d'écriture des professionnels de 
la conservation sur leur propre univers: histoire de leurs institutions, de leurs bâtiments, biographies des prédécesseurs les plus marquants, histoire des techniques de conservation rentrent dans ce cadre. Selon les domaines du patrimoine, ces discours sur l'institution peuvent avoir fait l'objet de synthèses monumentales (comme pour les bibliothèques) ou au contraire de réflexions en pointillé (comme pour les archives). Selon une autre perspective, centrée quant à elle sur la production scientifique contemporaine dédiée au patrimoine, un tel numéro serait à placer en contrepoint comme une réflexion des professionnels sur eux-mêmes - des très nombreux travaux de recherche qui ont le patrimoine pour objet, en sciences économiques comme en droit, en sociologie, en géographie, ou bien entendu en histoire. Dans cette configuration centripète, l'ethnologie occupe une place à part, puisque, au cours des trente dernières années, elle est passée du statut de discipline patrimoniale (ayant le patrimoine ethnologique comme cause à servir) à celui de science du patrimoine (ayant le patrimoine comme objet à déconstruire). Ainsi, une relation peut être établie, pas entièrement fortuite, entre la parution du présent numéro d'In Situ et le volume récemment consacré aux métiers du patrimoine publié dans la collection des Cahiers d'ethnologie de la France ${ }^{5}$, au point que certaines contributions se répondent d'un ouvrage à l'autre, poursuivant à distance le travail de rapprochement et d'interaction amorcé par la sociologue et la restauratrice dans le présent volume.

7 Le patrimoine n'est pas né de la professionnalisation de ses acteurs, mais d'une sensibilité accrue des citoyens au patrimoine national puis local. Ce volume ne le découvre pas mais le confirme: quelques contributions (Cécile Robin, Pascal Riviale) rappellent le rôle décisif du monde des amateurs, des associations, qui participent aux processus de patrimonialisation. Mais la "patrimonialisation» a professionnalisé les acteurs, comme l'archiviste (Julie Lauvernier) ou ceux qui avaient la charge des musées (Géraldine Masson, Amandine Péquignot). Cette professionnalisation des défenseurs du patrimoine est toujours en cours: elle a conduit d'une part à marginaliser progressivement les "amateurs » au bénéfice des "professionnels ", et d'autre part à mettre en avant des individus ayant bénéficié d'une formation spécifique (dispensée par l'Institut national du patrimoine (INP), l'École du Louvre, l'École des chartes, et aujourd'hui, dans l'immense majorité des cas, l'université).

Ce processus répond aux évolutions de l'action publique et des attentes du public, qui ont donné naissance à de nouvelles missions (Nicolas Navarro), et donc de nouvelles qualifications et de nouveaux métiers (régisseur d'œuvres, guide-conférencier), pour aboutir - stade suprême de la reconnaissance socioprofessionnelle en France - à de nouveaux statuts (chargés de protection, conservateur-restaurateur). Ces femmes et ces hommes, en quête constante de légitimité, sont unis dans la défense du patrimoine, tout en ayant des exigences et en étant sensibles aux concurrences professionnelles, comme le montre l'apparition du métier de médiateur culturel, de régisseur d'œuvres, ou la revendication du statut de conservateur-restaurateur. Si la posture corporatiste affleure ça et là, ces textes ne se résument pas à cela : leurs rédacteurs déclarent au contraire que c'est bien le souci de la défense des patrimoines et de leur transmission au public qui est au cœur de leur réflexion.

Un des points communs de ces textes est de souligner la richesse et l'extraordinaire complexité de l'organisation de la formation supérieure en France et son effet déterminant sur ces concurrences professionnelles. Depuis le xix ${ }^{e}$ siècle et tout au long $\mathrm{du} \mathrm{xx}^{\mathrm{e}}$ siècle, l'hétérogénéité professionnelle s'était déjà confortée par une 
multiplication des formations, traduisant une forme de concurrence : l'École nationale des chartes, l'École du Louvre, l'École de Chaillot, l'Institut national du patrimoine (Paris et Aubervilliers), l'École nationale supérieure des sciences de l'information et des bibliothèques (ENSSIB, Villeurbanne). À partir des années 1980, nous avons changé d'échelle mais aussi de périmètre institutionnel. La décentralisation a donné naissance aux centres régionaux de formation aux carrières des bibliothèques et au réseau du Centre national de formation professionnelle territoriale (CNFPT). Les universités (DUT, licences et masters) ont accompagné le développement de l'emploi culturel et la naissance de nouveaux métiers dans le patrimoine, sans réelle concertation avec le ministère de la Culture ou ses représentants. C'est ce que démontre l'étude de Philippe Tanchoux et de Florence Abrioux sur l'offre de formation dans ce domaine (526 diplômes répertoriés en 2014). Or, avec ou sans le soutien du ministère de la Culture, il n'en demeure pas moins que cette offre participe à la professionnalisation accrue des acteurs du patrimoine, comme l'expose Bénédicte Grailles à propos des formations en archivistique.

10 En 2016, la plus grande part des formations dédiées à la connaissance, à la conservation et à la restauration du patrimoine sont dispensées dans des établissements qui relèvent de l'Enseignement supérieur, l'Institut national du patrimoine, sous tutelle du ministère de la Culture, faisant plutôt figure d'exception dans un panorama d'offres dominé par les formations dédiées aux arts en général ou à l'architecture en particulier (et il faudrait évoquer ici le cas particulier de l'École de Chaillot, attachée à la Cité de l'architecture et du patrimoine) $)^{6}$. La distinction entre formations universitaires et écoles spéciales n'est pas non plus pertinente pour rendre compte du découpage entre ministères de tutelle, puisque l'École nationale des chartes (point de départ de la carrière de nombreux conservateurs dans différentes spécialités) et l'ENSSIB (pour les conservateurs des bibliothèques) sont sous l'autorité du ministère chargé de l'Enseignement supérieur. Enfin, les organismes de formation des collectivités territoriales jouent également un rôle important dans la formation des conservateurs, puisque l'Institut national des études territoriales (INET) est désormais responsable de la formation des conservateurs territoriaux des bibliothèques.

11 Dans son exposé des motifs, la loi relative à la liberté de la création, à l'architecture et au patrimoine (LCAP) qui vient d'être votée prend acte du rôle central de la formation professionnelle dans la vie et le développement culturel $^{7}$. Le lecteur de ce volume pourra légitimement s'en féliciter. Mais il pourrait aussi s'étonner de l'oubli d'établissements rattachés à l'Enseignement supérieur, alors qu'ils sont depuis les années 1980 un lieu majeur de formation de ces acteurs.

\section{NOTES}

1. - Comité d'organisation: Marie-Cécile Bouju (université Paris-8), Bernadette Dufresne (université Paris-8), Christian Hottin (ministère de la Culture), Rosine Lheureux (Archives nationales), Elsa Marguin-Hamon (Archives nationales), Christophe Pavlidès (Médiadix). 
2. - Sur l'existence des "métiers de la culture », nous renvoyons à la thèse de doctorat d'Isabelle Mathieu : L'Action culturelle et ses métiers. Paris : PUF, 2011.

3. - Chiffres clés 2016: Statistiques de la culture et de la communication. Paris : ministère de la Culture et de la Communication, DEPS, 2016.

4. - POULOT, Dominique. Une histoire du patrimoine en Occident, XVIII $-\mathrm{XXI}^{e}$ siècles. Du monument aux valeurs. Paris : PUF, 2006.

5. - Le tournant patrimonial. Mutations contemporaines des métiers du patrimoine. Paris : Éditions de la MSH, 2016 (collection « Cahiers d'ethnologie de la France, 29).

6. - Cette originalité de l'INP est renforcée par le fait que c'est le seul établissement voué, en raison de son histoire institutionnelle complexe, tout à la fois à la conservation et à la restauration des œuvres, du fait de l'intégration, en 1995, de l'Institut français de restauration des œuvres d'art (IFROA), établi par Valéry Giscard d'Estaing en 1977 (et initialement placé sous la tutelle de la Délégation aux arts plastiques du ministère de la Culture).

7. - Loi n²016-925 du 7 juillet 2016. Voir le site : https://www.legifrance.gouv.fr/affichTexte.do? cidTexte=JORFTEXT000032854341\&categorieLien=id.

\section{AUTEURS}

\section{MARIE-CÉCILE BOUJU}

Maître de conférences en histoire contemporaine, Département d'Histoire. UFR Textes et sociétés, Directrice du master Archives, Université Paris-8-Vincennes-Saint-Denis mariececile.bouju02@univ-paris8.fr

\section{CHRISTIAN HOTTIN}

Conservateur en chef du patrimoine, adjoint au département du pilotage de la recherche et de la politique scientifique, direction générale des Patrimoines, ministère de la Culture et de la Communication. Désormais directeur des études (conservateurs), Institut national du patrimoine christian.hottin@inp.fr 